\title{
The hydrogen solution?
}

\author{
A new star has exploded back onto the climate scene: hydrogen. It offers possibilities to move away from fossil \\ fuels, but it brings its own challenges.
}

or climate experts, green or renewable hydrogen - made from the electrolysis of water powered by solar or wind - is indispensable to climate neutrality. It features in all eight of the European Commission's net zero emissions scenarios for 2050 ( ref. $^{1}$ ). In theory, it can do three things: store surplus renewables power when the grid cannot absorb it, help decarbonize hard-to-electrify sectors such as long-distance transport and heavy industry, and replace fossil fuels as a zero-carbon feedstock in chemicals and fuel production.

Europe is leading the global resurgence of an energy carrier, with origins back in World War II. Hydrogen was originally used by the Nazis to produce synthetic fuels from coal. Today, it is back in business. The International Energy Agency lauded its "vast potential" in a first ever report on hydrogen in June 2019 (ref. ${ }^{2}$ ). Bloomberg New Energy Finance said clean hydrogen "can help address the toughest third of global greenhouse gas emissions by 2050" in March 2020 (ref. $^{3}$ ).

"Europe is the laboratory," says Emmanouil Kakaras, head of new business at
Mitsubishi Power Europe and member of an internal task force dedicated to carbon-free fuels. "We look at it as the place where technology and especially policy can be tested and pave the way for global deployment."

The hydrogen economy is a priority for the EU's post-COVID-19 economic recovery package ${ }^{4}$; this package is guided by the European Green Deal, which commits Europe to become the world's first climate neutral continent by 2050 (ref. ${ }^{5}$ ). It is hard to overstate the difference with Europe's past goal, an $80-95 \%$ emission reduction by 2050 . Net-zero requires a full fossil fuel phase-out. It puts the spotlight on gas for the first time. And the gas industry is turning to hydrogen for a new lease of life.

"If Europe adopts a 55\% emission reduction target for 2030, Germany would have to reduce its heating emissions by half," says Eva Hennig, head of EU energy policy for Thuega, a network of local German utilities. "That is impossible with realistic renovation rates and just electricity. You will have to decarbonize gas for heating." Hydrogen is a lifebelt for regions such as the Northern Netherlands, with an expertise and infrastructure looking for a new purpose as earthquakes and climate change turn natural gas from boon to bane.

Yet the climate community is cautious. "The risk is that the [hydrogen] hype triggers a reversal of priorities," says Brussels-based Dries Acke, head of the energy programme at the European Climate Foundation, a philanthropic initiative to catalyse the transition to a climate-neutral economy. "Energy efficiency, renewables and direct electrification are the bulk solutions [to climate change]. Hydrogen comes in around that. Hydrogen is essential to get to net zero in certain sectors like industry, but we are talking about the last $20 \%$ of emission reductions."

Moreover, the climate impact of hydrogen depends entirely on how it is made. "There is a risk of policy before definitions," continues Acke. He warns that this could see hydrogen go the way of biofuels, which have suffered from start-stop policies because of intense debate over their net impact on climate change. "Hydrogen is not a technology, it is an energy carrier that can be produced clean or dirty," he says.

\section{Box 1 | Blue hydrogen: a controversial stepping stone}

Blue hydrogen revives the capture and storage (CCS) story. It is the production of 'decarbonized' hydrogen by applying CCS to the traditional route of making hydrogen via steam methane reforming. The European Commission calls CCS a "priority breakthrough technology" in its Green Deal and promises it fresh money in its COVID-19 recovery package.

The big difference with the past policymakers in Europe have already poured billions into the technology, with little to show for it - is the new hydrogen economy narrative, a shift in focus from the power sector to industry, and projects starting from the transport and storage rather than carbon capture perspective. The concept has moved from post- to pre-combustion CCS. This means the business case no longer depends entirely on the EU carbon price - never high enough - but also on the value of the blue hydrogen it produces.
The oil and gas industry is one of the biggest supporters of blue hydrogen because it offers them a path towards clean fuels while drawing on their existing gas production, transport and storage facilities. "What we are risking [with CCS] is a rapid decarbonization of gas," joked Per Sandberg from Norwegian oil and gas giant Equinor at a CCS event in the European Parliament in Brussels in January 2020.

Many argue that blue hydrogen is essential to build up a market for what will ultimately be green hydrogen. The climate community is divided, however. From a climate perspective, the problem of blue hydrogen is that it depends on CCS and natural gas. First, commercially viable CCS remains an aspiration rather than a reality, and second, carbon capture can never be $100 \%$ efficient. At the same time, there is great uncertainty over the climate impact of upstream methane leakage.
Methane is the most important short-lived climate pollutant. Methane emissions in 2020 will cause half the global warming over the next 20 years, according to the US-based NGO the Environmental Defense Fund. The oil and gas industry is the second biggest source of methane emissions after agriculture and the easiest one to tackle. Forty per cent of the industry's emissions could be avoided at no net cost, estimates the International Energy Agency ${ }^{12}$.

The EU is working on a methane strategy. Reducing methane emissions could play a "very significant role" in enabling it to increase its climate ambitions for 2030, an EU official said in November 2019. "The credibility of gas is on the line," said Mónika Zsigri from the Commission's energy department. "Methane leakage determines how interesting gas is versus jumping directly to renewables." It also determines how interesting blue hydrogen is versus green. 
There are three main types of hydrogen discussed today. First, 'grey' hydrogen. The vast majority of hydrogen in use - and there is plenty of it, mainly in industry - is made from natural gas. The process emits $\mathrm{CO}_{2}$. Second, 'blue', or as the gas industry likes to call it, 'decarbonized', hydrogen is made from natural gas with carbon capture and storage (CCS) (see Box 1). Finally, 'green' or 'renewable' hydrogen - which every hydrogen advocate says is the ultimate goal - is made from the electrolysis of water powered by renewables.

There are other colours. The main one on the horizon is 'turquoise' hydrogen made from molten metal pyrolysis. This is the thermal cracking of natural gas into hydrogen and solid carbon. Its appeal is twofold: one, it does not require CCS, and two, instead of $\mathrm{CO}_{2}$ it produces a material that has been on the EU's critical raw materials list for years (as 'natural graphite'). Big corporates such as Russia's Gazprom and Germany's BASF are looking into it, but this is a technology that is still in its infancy.

\section{Making the business case}

For some such as Samuele Furfari, professor in energy geopolitics at the Université Libre de Bruxelles in Belgium, hydrogen of any colour makes little sense. It makes much more sense to use fossil fuels or electricity directly. "Each [conversion] step is a waste of energy," he says. "The processes are technically feasible but they are nonsense from an energy and economic point of view. Hydrogen has re-emerged because we need a solution to the intermittency of renewables."

Ad van Wijk, professor for future energy systems at Delft University of Technology in the Netherlands and a founding father of the hydrogen economy concept, counters that efficiency is no longer the benchmark: "a solar panel in the Sahara generates 2-3 times as much power as one in the Netherlands. If you convert that power to hydrogen, transport it here and turn it back into power via a fuel cell, you are left with more energy than if you install that solar panel on a Dutch roof. In a sustainable energy system, you calculate in terms of system costs, not efficiency."

van Wijk sums up: "even if all production and consumption was electric, more than half of that power would have to be converted to hydrogen for [cost-effective] transport and storage." Electricity cables can transport up to 1-2 GW, but the average gas pipeline can carry $20 \mathrm{GW}$ (and is 10-20 times cheaper to build). The challenge is converting existing gas pipelines from natural gas to hydrogen, says van Wijk.

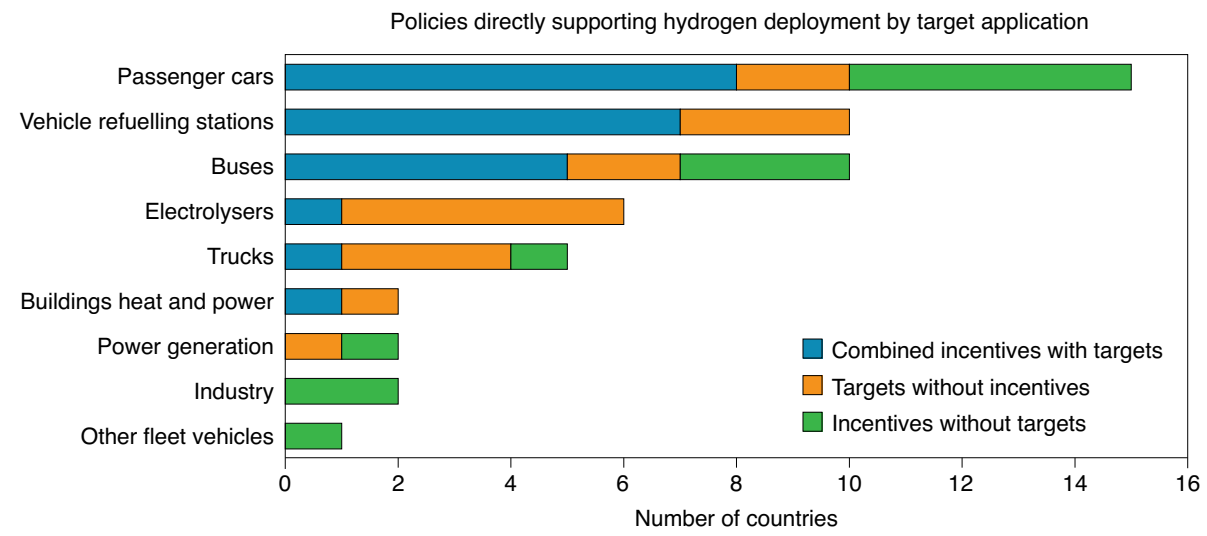

Fig. 1 | Policies directly supporting hydrogen deployment by target application. Based on available data up to May 2019. Credit: IEA (2019). The Future of Hydrogen; Seizing today's opportunities. All rights reserved

Nevertheless, clean hydrogen faces a paradox in its business case. The potential volumes are in industry, while the potential profit margins are in transport. Energy-intensive industries are the biggest hydrogen consumers today. With Europe aiming for climate neutrality in 2050 , there is growing interest in clean hydrogen from sectors such as steel and chemicals (over half of all the hydrogen worldwide is used in fertilizer production and oil refining). Yet these are also extremely price-sensitive industries exposed to global competition. Companies are not prepared to pay several times the 'grey' price for a climate-friendly alternative.

"There is a push from heavy industry to get green hydrogen into road transport so private car owners bear some of the early costs," says Philipp Niessen, director for industry and innovation at ECF. "But we believe it will be a scarce resource and it makes more sense to grow demand in sectors such as heavy industry where there is no decarbonization alternative."

"There is momentum for a political compromise around steel," Niessen adds. The European steel industry is suffering from ageing assets, over-capacity and Chinese competition. "Public support for clean steel could help the European industry rebuild its assets, first to run on gas and from the mid-2030s, on clean hydrogen." So far steel production is still coal-based.

Few believe that private cars will run on hydrogen in future. They are widely expected to go electric. Instead, trucks are the battleground. Truck makers such as Volvo and Daimler and logistics giants such as Deutsche Post DHL and Schenker told a conference in Brussels in February 2020 that for them, the future of freight is electric and for long haul, electric plus hydrogen. The advantage of electric trucks is that they are already available today, they said. In contrast, oil and gas suppliers argue that 'low-carbon liquid fuels', which increasingly means synthetic fuels or 'e-fuels' made from renewable hydrogen, are the way forward.

In practice, the Commission is considering mandating EU member states to roll out an electric charging infrastructure for trucks and blending quotas for sustainable fuels in aviation and shipping. Stakeholders agree that e-fuels are essential to decarbonize planes and ships in the long run. Along with heavy industry, emissions from these two sectors are the hardest and most expensive to abate.

\section{Policy dependent}

The emergence of a clean hydrogen economy depends on regulation (see Fig. 1 for distribution of policies in place mid-2019). "The biggest challenge is getting the right policies in place," says van Wijk. "We need to build up a hydrogen infrastructure. That is a huge task that needs political support." The first-ever European hydrogen strategy, released in July 2020 (ref. ${ }^{6}$ ), aims to support the broader goal of 'sector integration'. This originally meant using carbon-free power to help decarbonize other sectors, such as transport and industry. But it has become a broader bid to delineate roles for electricity and 'molecules' in the future energy system.

A new EU industrial strategy in March 2020 named the decarbonization of industry a 'top priority'. "Industry has some of the longest-lived assets," explains Matthias Deutsch, a senior associate and hydrogen expert at Agora Energiewende, a German think tank dedicated to the energy 
transition. "Production plants can run for 30-40 years. That means there will be investments in this decade that determine the climate footprint of industries in 2050. We need to give them a long-term outlook."

There is another industrial dimension: Europe is the global leader in electrolysis technology. It has filed about twice as many patents and publications as its nearest competitors - the US, China and Japan over the last 10-15 years?. "Electrolysers will become one of those critical technologies like solar, wind and batteries," says Acke. "Europe has a competitive advantage and it can maintain it." Nevertheless, there are those who already warn of strong competition from China.

The green hydrogen economy needs tailored support. "EU policy is trying to repeat the success story of renewables," says Kakaras. "But there is a big difference: unlike solar and wind, green hydrogen production is driven by operational not capital expenditure. Eighty per cent of the cost depends on the electricity price." Subsidies to promote large-scale deployment might bring down the cost of electrolysers, but this will not necessarily make green hydrogen production cheaper.

Kakaras explains: "you need an electricity price which is expensive enough to make renewable power viable and low enough to make the hydrogen produced from it competitive with gas." In practice, it is not possible to do both, he adds. "Policymakers need to bridge the gap between the carbon-free fuel price and the gas price." In practice, stakeholders are converging on the idea of Contracts for Difference for green hydrogen.

Eurogas, representing the European gas industry, wants policymakers to set targets for renewable and decarbonized gas and let the market decide what works best for a variety of end-uses. Other stakeholders such as Agora Energiewende and ECF believe that hydrogen support should reflect the need to prioritize specific sectors. It must, after all, remain supplementary to energy efficiency, renewables and direct electrification.

One of the most controversial questions is the use of hydrogen in residential heating. Hennig says: "even if you blend in only $20 \%$ hydrogen - and reduce $\mathrm{CO}_{2}$ by only $6.5 \%$ as a result - that is better than nothing. Especially if it is possible without adapting end-user appliances." She argues that blending hydrogen into gas grids is essential to help ramp up clean hydrogen production and its transportation. Climate campaigners respond that houses should switch instead to more efficient heat pumps and district heating. Extending hydrogen to heating risks 'supersizing' Europe's energy infrastructure ${ }^{8}$.

\section{Renewables as game-changer}

The biggest challenge to green hydrogen is that it will require vast amounts of renewable power. The IEA estimates that meeting today's hydrogen demand through water electrolysis would require 3,600 TWh a year, or more than the EU's entire annual electricity production ${ }^{2}$. Imagine its use extended from industrial feedstock to energy carrier in industry, transport, heating and power production.

Stakeholders agree that Europe could never produce enough renewable power to run a self-sufficient hydrogen economy. The Commission assumes there is scope for 1,000 GW of offshore wind in the North Sea, half of that dedicated to electrolysis ${ }^{1}$. But a study by Agora Energiewende also warns that the number of offshore wind turbines expected in the German section of the North Sea after 2030 risks reducing their full-load hours from 4,000-5,000 to just 3,000 (ref. ${ }^{9}$ ).

From another perspective, hydrogen is increasingly seen as a way of bringing offshore wind to shore and relieving pressure on an already overloaded onshore grid. Some companies are exploring the possibility of building electrolysers right into the body of wind turbines. Green hydrogen gives renewables a business case when the electricity system on its own cannot. "Conversion to hydrogen is a kind of hedging for a renewables investor," says Kakaras.

In reality, the hydrogen economy is an international project. Cross-border cooperation can ensure North Sea wind farms get enough space. Scale and economics dictate that Europe is likely to import green hydrogen from North Africa and the Middle East, and e-fuels from as far afield as Australia and Chile.

One of the biggest questions is whether enough green hydrogen can be ready fast enough to make a difference to climate change. Niessen says: "we live within the constraint of carbon budgets. Electrolysers are not microchips. Of course, costs will go down significantly, but will they go down fast enough to meet the Paris climate goals?"

Many believe that blue hydrogen with appropriate climate safeguards has a transitional role to play. It could help kick-off different sectoral uses and bring down prices through economies of scale. "Blue hydrogen could help speed up industrial transformation," says Deutsch. "The worry is that if a lot of such low-carbon hydrogen becomes available, it may not be limited to the sectors that really need it." Today, grey hydrogen costs around $€ 1.50 \mathrm{~kg}^{-1}$, blue hydrogen $€ 2-3 \mathrm{~kg}^{-1}$ and green hydrogen $€ 3.50-6 \mathrm{~kg}^{-1}$. Consultants estimate that a $€ 50-60$ per tonne carbon price could make blue hydrogen competitive in Europe ${ }^{10}$.

"In my view, we get the system moving," says van Wijk. "As demand for hydrogen grows and green hydrogen gets cheaper, it will supplement and replace this fossil-based hydrogen." Japan, who invested in hydrogen long before climate neutrality was on the agenda, is working with its main supplier, Australia, to transition from grey to blue to green. "Green hydrogen will ultimately be cheaper than grey hydrogen because of very cheap power from wind and solar," says van Wijk. "That is the game-changer."

"If deep decarbonization is on the societal agenda, then hydrogen will come," believes Kakaras. It is not about the laws of thermodynamics but whether society is willing to pay for climate neutrality. Michael Moore's documentary Planet of the Humans suggests that 'less is more' is the only long-term answer to climate change. But the COVID-19 lockdowns demonstrated just how big an ask this is: emissions dropped dramatically but did little for climate change ${ }^{11}$.

There is an opportunity here, however. As Furfari puts it: "the Green Deal was an opportunity for politicians to spend public money. The COVID-19 crisis gives them license to spend as much as they want."

Sonja van Renssen $\square$

Freelance journalist, Brussels, Belgium.

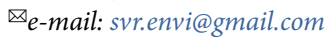

Published online: 27 August 2020 https://doi.org/10.1038/s41558-020-0891-0

References

1. A Clean Planet for all: A European Long-term Strategic Vision for a Prosperous, Modern, Competitive and Climate Neutral Economy (European Commission, 2018)

2. The Future of Hydrogen (IEA, 2019).

3. Hydrogen Economy Outlook: Key Messages (Bloomberg L.P., 2020).

4. Europe's moment: repair and prepare for the next generation. European Commission https://bit.ly/31vlPNz (2020).

5. A European Green Deal. European Commission https://bit.ly/ 3fCJIYL (2020).

6. A Hydrogen Strategy for a Climate-neutral Europe (European Commission, 2020).

7. Biebuyck, B. FCH-JU making hydrogen and fuel cells an everyday reality. Fuel Cells and Hydrogen Joint Undertaking https://bit.ly/3kgTJOE (2019).

8. Towards Fossil-Free Energy In 2050 (European Climate Foundation, 2019)

9. Making the Most of Offshore Winds: Re-evaluating the Potential of Offshore Wind in the German North Sea (Agora Energiewende, Agora Verkehrswende, Technical University of Denmark and Max-Planck-Institute for Biogeochemistry, 2020).

10. Peters, D. et al. Gas Decarbonisation Pathways 2020-2050: Gas for Climate (Guidehouse, 2020).

11. Le Quéré, C. et al. Nat. Clim. Change 10, 647-653 (2020).

12. Methane Tracker 2020 (IEA, 2020).

Competing interests

The author declares no competing interests. 